\title{
Alpine Glacier Mass Changes During the Past Two Millennia
}

\author{
Wilfried Haeberli and HaNSpeter Holzhauser
}

Institute of Geography, University of Zürich, 8057 Zürich, Switzerland; haeberli@geo.unizh.ch; holzi@geo.unizh.ch

The advance and retreat of mountain glaciers during historical and Holocene time periods reflect preindustrial changes in ice mass and corresponding energy fluxes. Quantitative data analysis can be based on a simple approach comparing assumed steady state situations separated by time intervals of decades to a century. Detailed information spaning the past two millennia is available for the Great Aletsch Glacier, the largest glacier in the European Alps, including an extraordinary number of absolute age and geometry determinations from historical documents, radiocarbon dating of fossil trees and tree-ring analyses. Rates of mass change and associated energy fluxes, during the $20^{\text {th }}$ century as a whole, lie between the average and the extreme of historical values, but appear to have recently increased beyond these limits.

\section{Glacier Fluctuations and Climate Change Detection}

Volume and mass changes of mountain glaciers represent key variables within global climate monitoring programmes, especially with respect to strategies for early detection of an enhanced greenhouse effect (Haeberli et al., 2000). Such strategies require quantitative information on both current and past rates of change. Overall energy fluxes associated with annual changes in ice thickness can be estimated based on a latent heat content of $3.338 \times 10^{5} \mathrm{~J} / \mathrm{kg}$. Thus, an annual change in ice thickness of 0.1 meters roughly corresponds to an additional energy flux of 1 $\mathrm{W} / \mathrm{m}^{2}$ irrespective of the details of the complex energy exchange processes involved. Direct determination of glacier mass changes began with the advent of modern cartography and repeated mapping of a few glaciers in the Alps at the end of the past century. In most regions of the world quantitative information became available only much later. Information on pre-industrial mass changes of mountain glaciers must

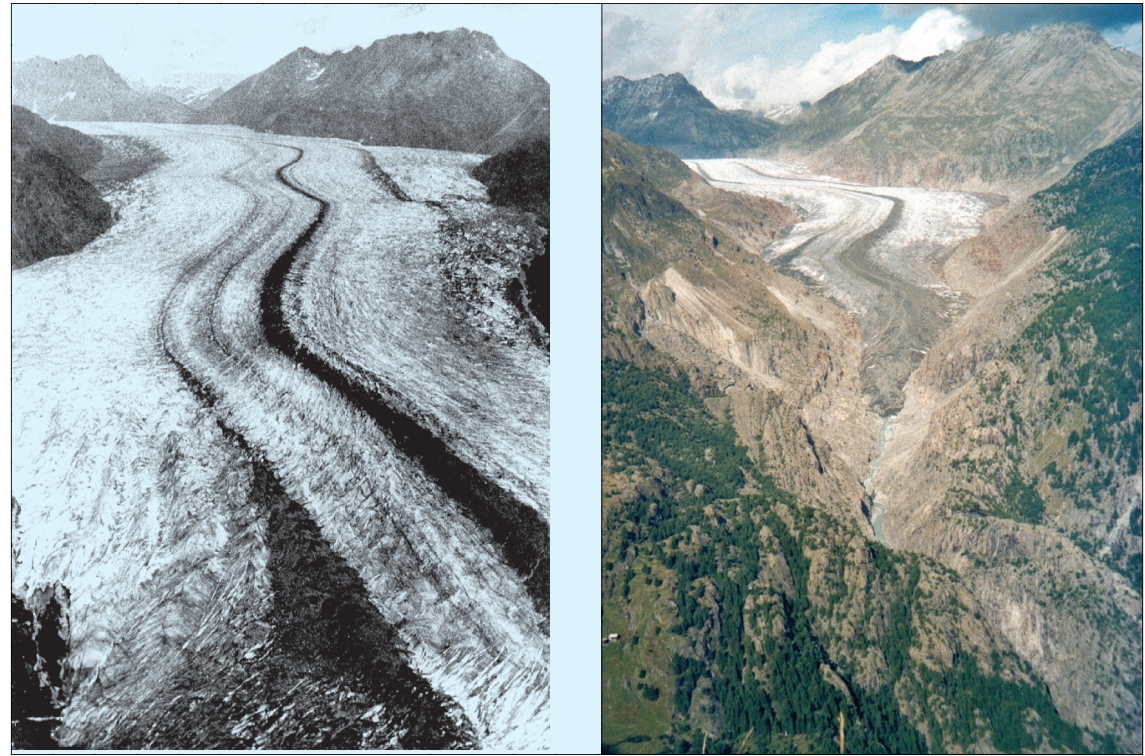

Fig. 1: The Great Aletsch Glacier seen from Belalp around 1856 and in 2001 (Photographs taken by Fréderic Martens, Alpine Club London, and Hanspeter Holzhauser).

therefore be deduced from records of cumulative changes in glacier length (advance and retreat) which reach further back in time.

Curves of cumulative glacier advance and retreat can be converted into time series of temporally averaged mass balance by applying a continuity model and considering stepwise changes associated with full dynamic response and establishment of new equilibrium conditions. According to this method, a mass balance disturbance ( $\partial \mathrm{b}$ ) leading to a corresponding glacier length change $(\partial L)$ depends on the original length (Lo) and the annual mass balance (ablation bt) at the glacier terminus: $\partial b=b t x$ $\partial \mathrm{L} /$ Lo. The dynamic response time is $h / b t$, where $h$ is a characteristic ice thickness, usually taken at the equilibrium line where ice depths are near maximum. Assuming a linear adjustment of the mass balance $b$ to zero during the dynamic response, the average mass balance $\langle b>$ is taken as $\partial b / 2$. This value $<b>$ is given in annual ice thickness change (meters of water equivalent per year) averaged over the entire glacier surface, and can be directly compared with values measured in the field (cf. Hoelzle et al., 2003 for details, calibration and application to worldwide observations during the $20^{\text {th }}$ century). The main limitation is time resolution. For example the Great Aletsch Glacier has a characteristic ablation at the terminus (bt) of 12 meters per year and a maximum thickness (h) of about 900 meters (at Konkordiaplatz close to the equilibrium line), thus the response time is somewhere between 50 and 100 years.

\section{Historical Fluctuations of the Great Aletsch Glacier}

Past glacier length changes can best be documented in cases of glaciers advancing into forested or cultivated areas (Fig. 1). Direct radiocarbon dating and dendrochronological analysis of formerly overridden and now reappearing tree trunks greatly help with the reconstruction of former ice geometries based on historical sources and moraine investigations. An especially detailed record is available for the Great Aletsch Glacier (Holzhauser, 1997). The Great Aletsch Glacier with a length of around $23,2 \mathrm{~km}$ and a surface area of approximately $86 \mathrm{~km}^{2}$, is the largest glacier in the European Alps. In the past, its tongue repeatedly reached 


\section{Science Highlights}

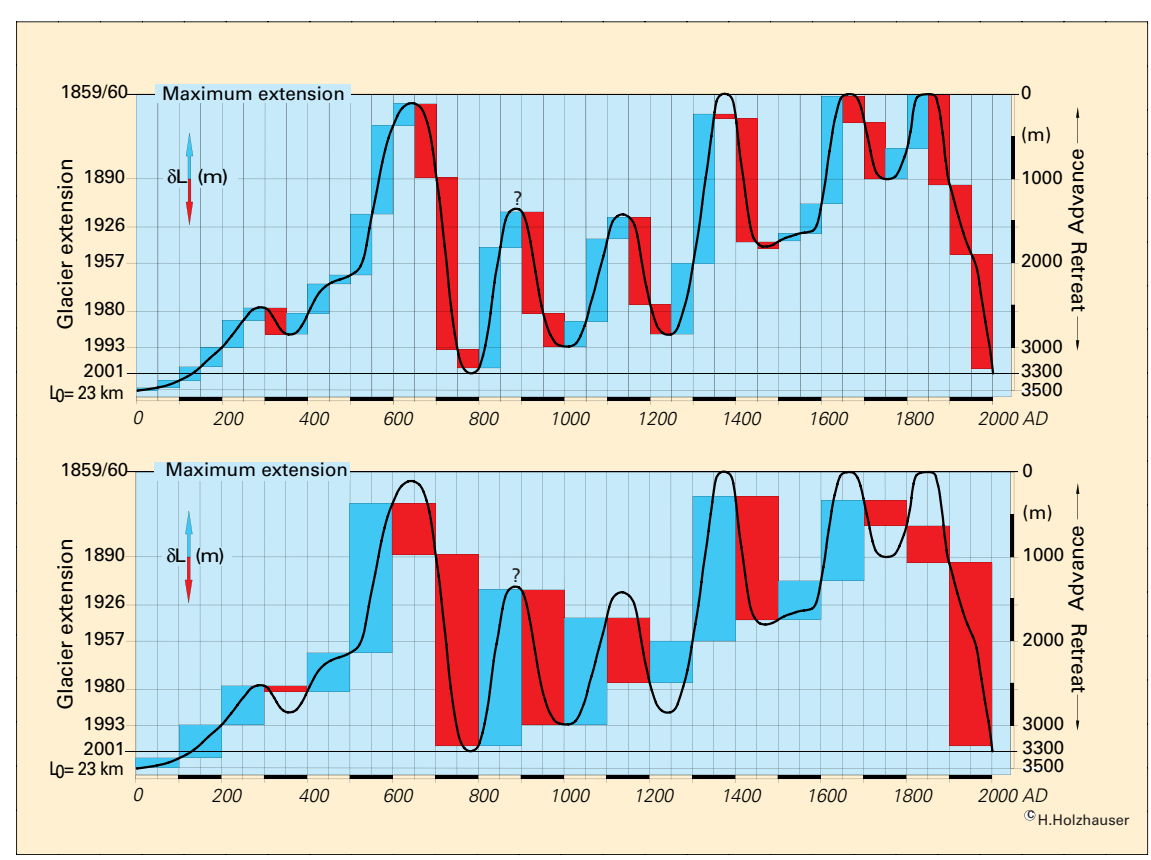

Fig. 2: Fluctuations of the Great Aletsch Glacier during the last 2000 years reconstructed with historical documents and dendrochronologically/absolutely dated fossil wood. Average mass balance calculated for time intervals of 50 years (on top) and of 100 years (below).

deeply into stands of coniferous forest, sometimes coming very close to inhabited areas and destroying mountain huts, affecting a regionally important irrigation channel or covering forests and arable land. Such conditions enable glaciological methods (geodetic surveying, detailed topographic mapping), historical and archaeological sources (written and pictorial historical records), geomorphological evidence (dated organic material from overriden soils and crushed trees within, and at the edge of, areas becoming ice-free) to be combined to reconstruct a detailed time series of cumulative changes in the length of the Great Aletsch Glacier over the past two millennia (Fig. 2). Only roots, stumps and trunks of trees found in their original place of growth (in situ) are suitable for the exact reconstruction of past glacier fluctuations, because complex transportation paths from the place of growth to the place of reappearance are of no concern. The accuracy of such reconstructions generally decreases further back in time.

From 1892 to the present, the continuously decreasing tongue length has been precisely measured every year, providing an exceptional record for the last century. The so defined retreat covers a substantial period of previous variability, thereby enabling evidence from earlier times to be related to stages measured in modern times. Historical pictures and texts document fluctuations during the $18^{\text {th }}$ and $19^{\text {th }}$ centuries, especially the final advance to the last "Little Ice Age" maximum extent around 1856. Dendrochronological analysis allows an exact reconstruction standard deviation of the mean. of the marked advance leading to a maximum glacier extent from 1670 to $1680 \mathrm{AD}$ (Holzhauser and Zumbühl, 1999). A very small advance around $1500 \mathrm{AD}$ is dated by both, dendrochronology and archaeology (destruction of an irrigation channel). Sparse evidence from the $15^{\text {th }}$ century consists of written documents indicating that the glacier size was similar to that of the 1940's. The time period between the year 0 to the end of the $14^{\text {th }}$ century is exclusively reconstructed by dendrochronologically absolutely dated fossil wood. The "Medieval Warm Period" from around $800 \mathrm{AD}$ to the onset of the "Little lce Age" around 1300 AD was interrupted by two weak advances.

\section{Past Variabilities and Beyond}

The reconstructed cumulative length changes of Great Aletsch Glacier show relatively regular ocillations of advance and retreat with characteristic amplitudes of one to two km and periods of around two centuries. Interannual and decadal climate variability are not registered due to the slow dynamic response of the relatively long glacier tongue. The glacier tongue is now approaching the previous minimum length of record as documented around the calendar year 0 . As a consequence, the overall mass change during the entire time of the considered two millennia is close to zero. Average rates of mass change modelled for 50- and 100-year time intervals (Fig. 2) provide a variability (standard deviation of the mean, Table 1) of a few decimeters of gain/ loss per year (corresponding to a few $\mathrm{W} / \mathrm{m}^{2}$ towards/away from the surface) with extremes near half a

Table 1: Reconstructed average mass balance $b(\mathrm{~m} / \mathrm{y})$ of the Great Aletsch Glacier during the last 2000 years. The values for 1980 - 2000 are doubled values for the $20^{\text {th }}$ century, $\pm \partial$ is the

\begin{tabular}{|l|c|c|c|c|c|}
\hline \multirow{2}{*}{$\begin{array}{l}\text { Considered } \\
\text { Time Step }\end{array}$} & \multicolumn{4}{|c|}{ Mean Mass Balance Change (m weq/year) - during the past 2000 years } \\
\cline { 2 - 6 } & $\pm \partial$ & Maximum & Minimum & $20^{\text {th }}$ Century & $1980-2000$ \\
\hline $\mathbf{5 0}$ years & \pm 0.31 & +0.43 & -0.48 & -0.26 & -0.52 \\
\hline 100 years & \pm 0.25 & +0.48 & -0.53 & -0.51 & -1.02 \\
\hline Mean & \pm 0.28 & +0.46 & -0.51 & -0.39 & -0.77 \\
\hline
\end{tabular}

meter per year. Mass losses during the $20^{\text {th }}$ century appear to be at the limits of the characteristic variability during the past two millennia if not close to extremes probably reached around 700 to $800 \mathrm{AD}$. Accelerated atmospheric warming could soon lead to rates of mass change beyond such historical extremes. In fact, directly measured mass losses of Alpine glaciers since 1980 have been comparable with a 
doubling of mean $20^{\text {th }}$-century loss rates (Haeberli et al. 1999, Fig. 3).

Critical points associated with this analysis include: (1) the choice of the starting/end point for the calculation/comparison (the model with the 50-year time interval obviously fits the curve better) and (2) the delay in the onset of terminus reaction to mass balance forcing (a few decades in the case of the Great Aletsch Glacier). The first effect means that an optimal fit has still to be found and the latter phenomenon indicates that today's terminus position of the large glacier reflects climatic conditions around the 1970s or so. In view of the rapid warming during the past two decades, it is highly probable that the glacier tongue would have to be hundreds of meters shorter than now in order to adjust to conditions around the year 2000. The previous minimum extent of Roman times may, therefore, soon be markedly exceeded.

\section{REFERENCES \\ Haeberli, W., Barry, R. and Cihlar, J., 2000: Glacier monitoring within the Global Climate Observing System. Annals of Glaciology, 31, 241 - 246. Haeberli, W., Frauenfelder, R., Hoelzle, M. and Maisch, M., 1999: On rates and acceleration}

trends of global glacier mass changes. Geografiska Annaler, 81A, 585 - 591

Hoelzle, M., Haeberli, W., Dischl., M. and Peschke, W., 2003: Secular glacier mass balances derived from cumulative glacier length changes. Global and Planetary Change $\mathbf{3 6}$ (4), 77 - 89.

Holzhauser, H., 1997: Fluctuations of the Grosser Aletsch Glacier and the Gorner Glacier during the last 3200 years: new results. In: Frenzel, $B$. (Hrsg.): Glacier fluctuations during the Holocene. Paläoklimaforschung/Palaeoclimate Research 24, 35-58. Special Issue: ESF Project European Palaeoclimate and Man 16. Gustav Fischer Verlag Stuttgart, Jena, Lübeck, Ulm

Holzhauser, H. and Zumbühl, H. J., 1999: Glacier fluctuations in the Western Swiss and French Alps in the 16th century. In: Pfister, C. / Brázdil, R. (eds.): Climatic Variability in Sixteenth-Century Europe and Its Social Dimension. Climatic Change 43, 223 $-237$.

\title{
Cyclical Climatic-Environmental Changes in the Mediterranean Area (2500 BP-Present Day)
}

\author{
Franco 0rtolani ${ }^{1}$ and Silvana Pagliuca ${ }^{2}$ \\ 'Dipartimento di Pianificazione e Scienza del Territorio, Università di Napoli Federico II, Napoli, Italy; fortolan@unina.it \\ ${ }^{2} I S A F O M, C N R$, via Cupa Patacca, Ercolano, Napoli, Italy; pagliuca@ispaim.na.cnr.it
}

The Mediterranean area acts as a boundary zone between humid and desert zones and is highly sensitive to variations in climate and environment. Indeed, shifts in the climate bands towards north or south by only a few degrees of latitude may result in dramatic changes in soil surface conditions. This may cause, for example, desertification in areas that previously had a humid climate or vice versa.

Multidisciplinary geoenvironmental research was carried out to shed light on the climatic significance of different sediment types that have accumulated over the last 2500 years (Fig. 1), located at various latitudes and in geographical areas with different morphoclimatic conditions (Ortolani et al., 1991; Ortolani and Pagliuca, 1993, 1994, 2001). The sediments, which cover many archaeological sites, were not affected by human impact between the Archaic Period and the Middle Ages.

In the Mediterranean area, the presence of wind-borne sand in coastal dunes (Als, Fig 1) is the most significant geoenvironmental indicator linked to warm-arid climatic conditions. Under conditions of heightened aridity (rainfall lower than $200 \mathrm{~mm}$, typical of

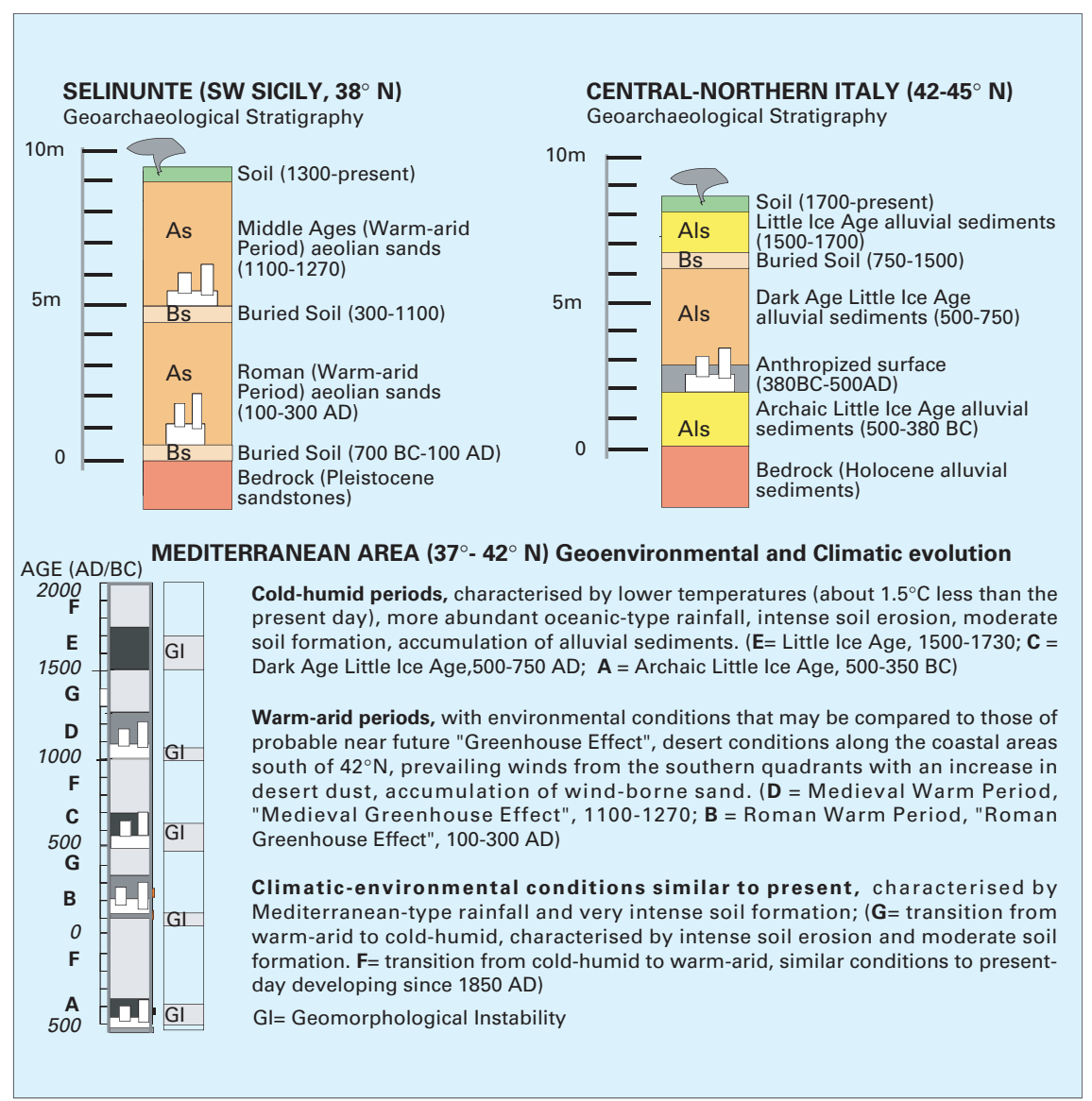

Fig. 1: Mediterranean Area Geoarchaeological Stratigraphy and Geonvironmental-Climatic Evolution (2500 BP-Present Day).

desert areas), wind-borne coastal sand may even invade areas a considerable distance from the sea, forming wind-borne accumulations that cause the vegetation cover to disappear. This has been widely shown in the literature and verified by direct research (Ortolani and Pagliuca, 2001). 